\title{
Tribridged diruthenium complexes: A new structural motif
}

\begin{abstract}
AKHIL R CHAKRAVARTY
Department of Inorganic and Physical Chemistry, Indian Institute of Science, Bangalore 560012, India

Abstract. Dinuclear complexes containing a ( $\mu$-oxo)bis( $\mu$-carboxylato) diruthenium (III) core have been prepared by a novel synthetic route using metal-metal bonded diruthenium(II, III) tetracarboxylates as precursors. The complexes have been structurally characterized and they are redox active. The terminal ligands play an important role in tuning the electronic structure of the core. The stability of the core is found to be dependent on the size and $\pi$-acidic nature of the terminal ligand cis- to the $\mu$-oxo ligand. The chemistry of such tribridged complexes is relatively new. The rapid growth of this chemistry is based on the discovery of similar core structures in several non-heme ironand manganese-containing metalloproteins. The tribridged core presents a new structural motif in coordination chemistry. The chemistry of diruthenium complexes with a $\left[\mathrm{Ru}_{2}(\mu-\mathrm{O})\left(\mu-\mathrm{O}_{2} \mathrm{CR}\right)_{2}^{2+}\right]$ core has been reviewed.
\end{abstract}

Keywords. Tribridged complexes; ruthenium; redox properties; $\mathrm{X}$-ray structures.

\section{Introduction}

Carboxylato complexes are of considerable importance in coordination chemistry. The major interests lie toward understanding the structure and bonding at the metal centres for modelling the active site structure of non-heme metalloproteins and in the development of homogeneous catalysts as well as advanced inorganic materials. In the ruthenium chemistry, two types of carboxylato bridged species, viz. I and II, have been studied extensively.

Trinuclear complexes have a basic acetate structure (Cannon and White 1988). The M-M bonded system has a "paddlewheel" core (Cotton and Walton 1993). The third type gives us the emerging class of ( $\mu$-oxo) bis $(\mu$-carboxylato) dimetal complexes. The carboxylate ligand in these complexes exhibits a syn-syn bridging mode. A comparison of the chemistry of the di- and trinuclear complexes reveals that the tribridged core could, in principle, be derived from both the other two types of complexes. However, the chemistry of the tribridged complexes has not been developed until recently. The chemistry of trinuclear "basic" acetate complexes, which are found to be efficient homogeneous cataiysts for various processes, and the presenting of models for three-centre spin interaction phenomena have had rapid development, while complexes containing the structurally related binuclear core have been only recently synthesised.

The chemistry of tribridged complexes has generated considerable current interest following the discovery of similar core structures in several non-heme iron- and manganese-containing metalloproteins (Stenkamp et al 1984). There has been a surge in research activities on model diferric complexes having a tribridged core (Kurtz 1990; Que and True 1990). Similarly, several dimanganese complexes are also reported (Wieghardt 1989, 1994). This has contributed greatly to our understanding of the 


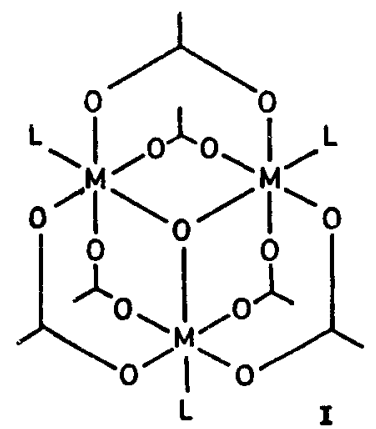

I

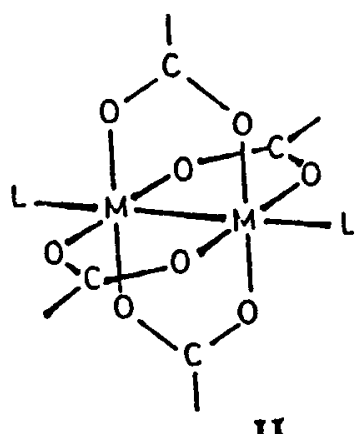

II

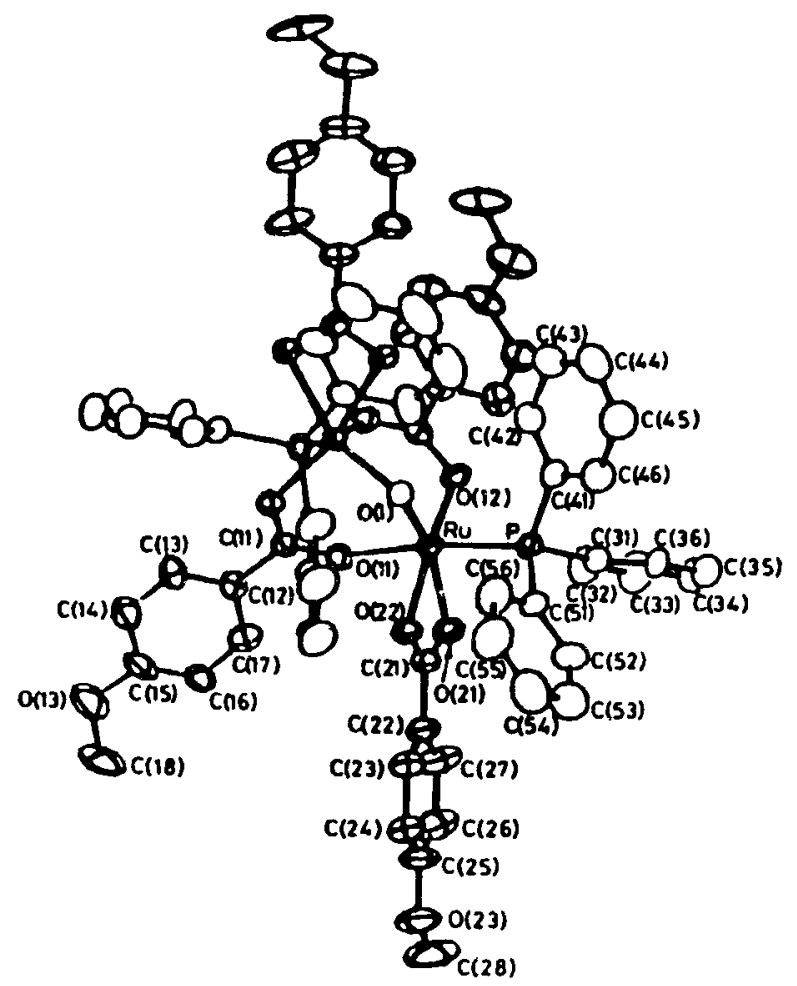

Figure 1. X-ray structure of $\left[\mathrm{Ru}_{2} \mathrm{O}\left(\mathrm{O}_{2} \mathrm{CC}_{6} \mathrm{H}_{4}-p-\mathrm{OMe}\right)_{4}\left(\mathrm{PPh}_{3}\right)_{2}\right]$.

fundamental aspects of this chemistry. We have been active in developing the related chemistry of diruthenium complexes. The diruthenium core can be stabilized in presence of unidentate as well as bidentate ligands in addition to the facially capping terdentate ligands. The $3 d$-metal complexes are known to be stable in presence of facially capping terdentate ligands. This report is based on our work in the chemistry of tribridged diruthenium(III) complexes. 


\section{Results and discussion}

\subsection{A new synthetic route}

Earlier work in the chemistry of tribridged diruthenium complexes has shown that a monomeric ruthenium complex can be dimerised in presence of carboxylate ligand (Llobet et al 1989; Wieghardt et al 1989; Sasaki et al 1991; Gupta et al 1992; Barral et al 1993). However, such reactions with unidentate ligands often lead to the formation of

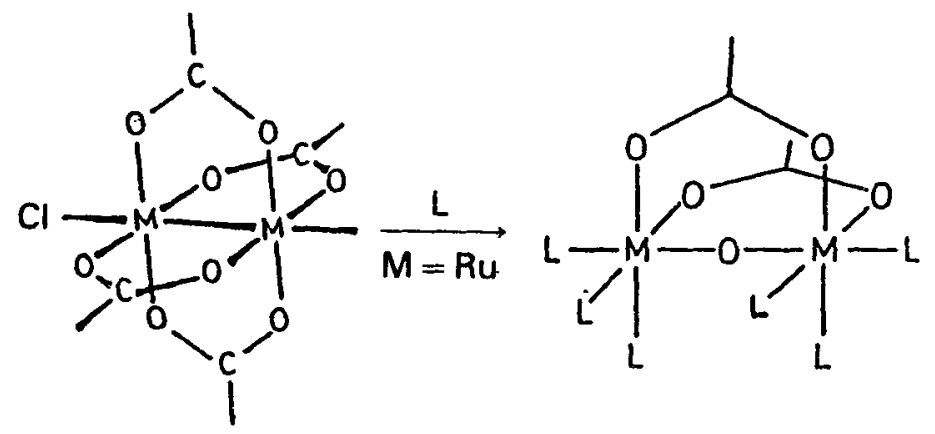

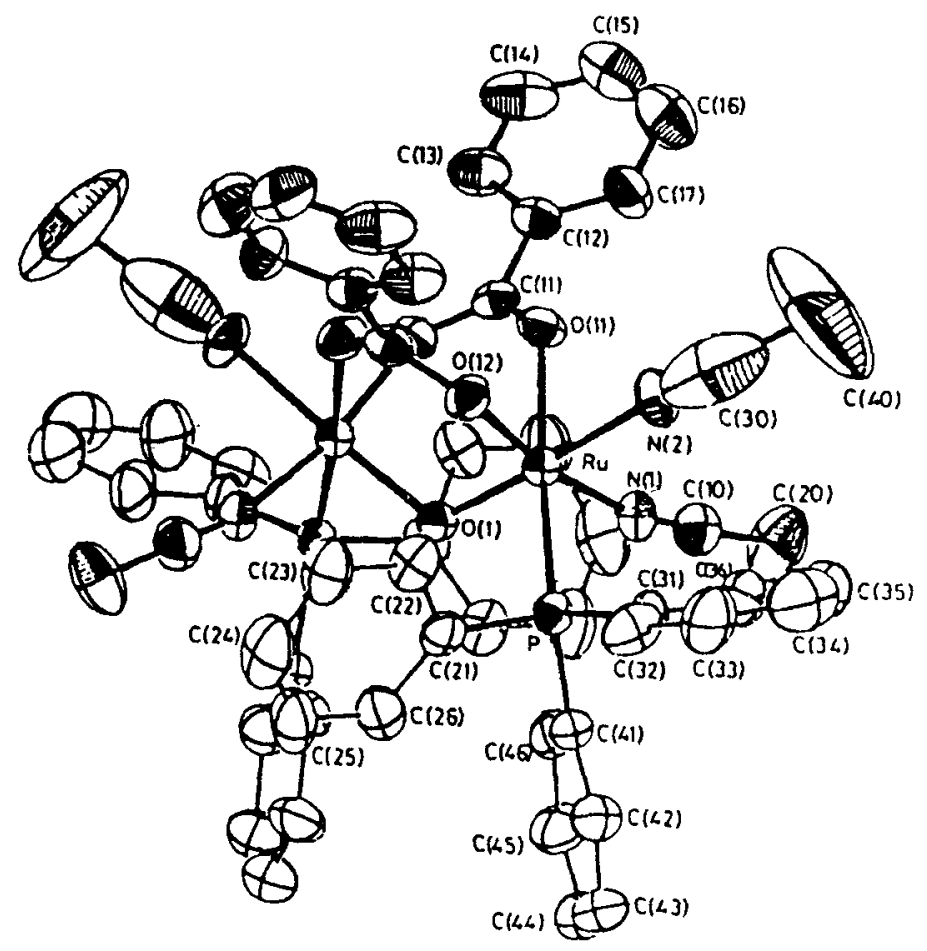

Figure 2. A view of the cationic complex of $\left[\mathrm{Ru}_{2} \mathrm{O}\left(\mathrm{O}_{2} \mathrm{CC}_{6} \mathrm{H}_{5}\right)_{2}(\mathrm{MeCN})_{4}\right.$ $\left.\left(\mathrm{PPh}_{3}\right)_{2}\right]\left(\mathrm{ClO}_{4}\right)_{2}$. 
side products. We have developed a new synthetic route for the synthesis of tribridged diruthenium complexes using tetracarboxylatodiruthenium(II, III) complexes as precursors. The $\mathrm{Ru}-\mathrm{Ru}$ multiple bonded core undergoes facile transformations in presence of $\mathrm{P}$ - and $\mathrm{N}$ - donor ligands to form a ( $\mu$-oxo)bis $(\mu$ - carboxylato) diruthenium(III) core (1). The formation of the tribridged core involves an oxo-bridge formation, substitution of two bridging carboxylato ligands by terminal ligands $(\mathrm{L})$ and a one-electron oxidation of the metal.

\subsection{Reaction of $\mathrm{Ru}_{2} \mathrm{Cl}\left(\mu-\mathrm{O}_{2} \mathrm{CR}\right)_{4}$ with $\mathrm{PPh}_{3}$}

In presence of triphenylphosphine, the precursor complex undergoes a core conversion to form $\left[\mathrm{Ru}_{2} \mathrm{O}\left(\mathrm{O}_{2} \mathrm{CR}\right)_{4}\left(\mathrm{PPh}_{3}\right)_{2}\right]$ (figure 1) in methanol and $\left[\mathrm{Ru}_{2} \mathrm{O}\left(\mathrm{O}_{2} \mathrm{CR}\right)_{2}\right.$ $\left.(\mathrm{MeCN})_{4}\left(\mathrm{PPh}_{3}\right)_{2}\right]\left(\mathrm{ClO}_{4}\right)_{2}$ (figure 2) in $\mathrm{MeCN}-\mathrm{NaClO}_{4}$ mixture (Das and Chakravarty 1990). The terminal carboxylate and acetonitrile ligands are labile and they can be substituted by 1,2-diaminoethane to give $\left[\mathrm{Ru}_{2} \mathrm{O}\left(\mathrm{O}_{2} \mathrm{CR}\right)_{2}(\mathrm{en})_{2}\left(\mathrm{PPh}_{3}\right)_{2}\right]\left(\mathrm{ClO}_{4}\right)_{2}$ (Syamala and Chakravarty 1993). The acetonitrile adduct under mild reaction condition undergoes a nucleophilic attack by en at the carbon of the $\mathrm{MeCN}$ cis to the

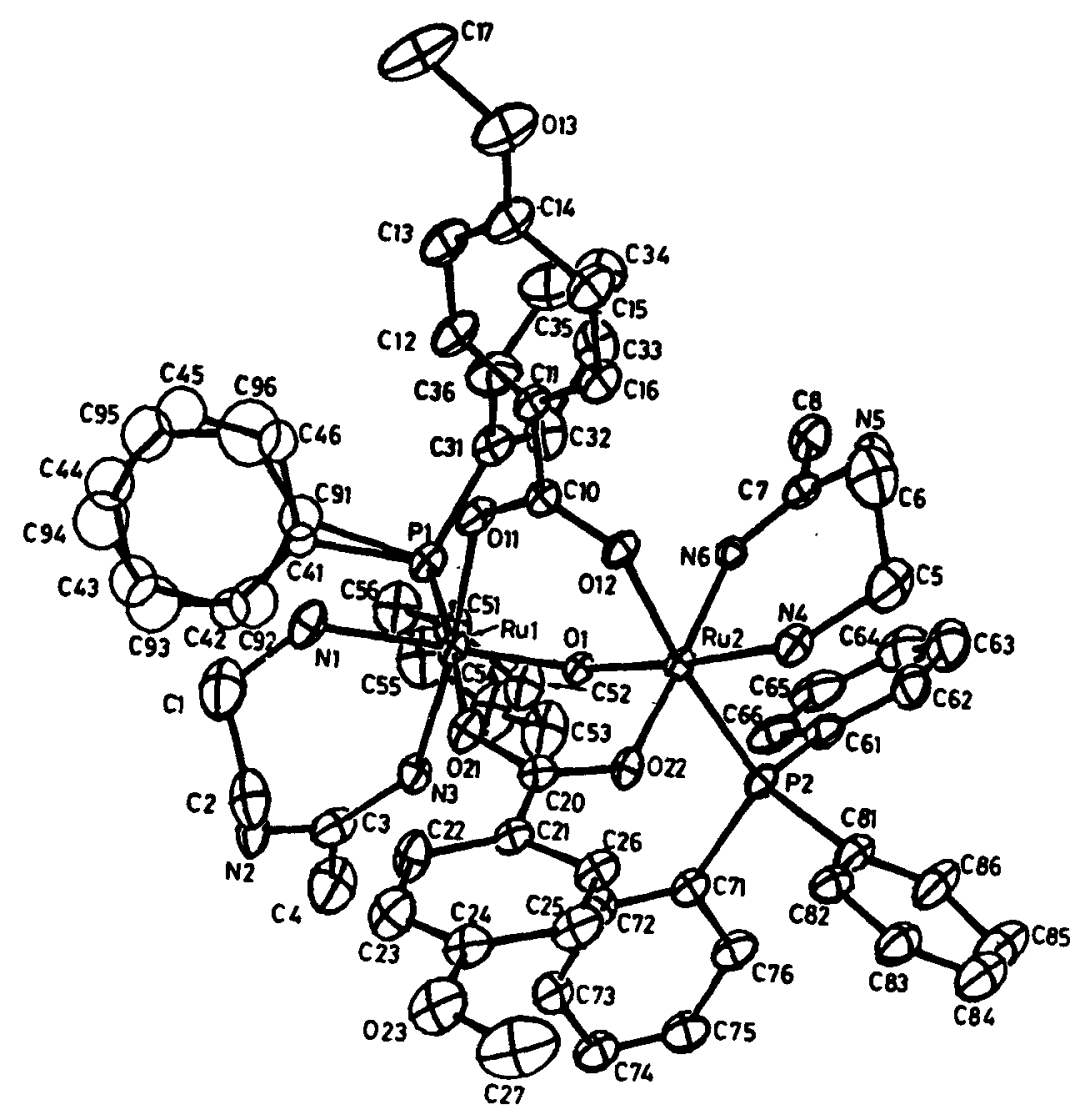

Figure 3. $\mathrm{X}$-ray structure of the cationic complex of $\left[\mathrm{Ru}_{2} \mathrm{O}_{(\mathrm{O}} \mathrm{OCC}_{6} \mathrm{H}_{4}-p\right.$ $\left.\mathrm{OMe})_{2}\left\{\mathrm{NH}_{2} \mathrm{CH}_{2} \mathrm{CH}_{2} \mathrm{NHC}(\mathrm{Me}) \mathrm{NH}\right\}_{2}\left(\mathrm{PPh}_{3}\right)_{2}\right]-\left(\mathrm{ClO}_{4}\right)_{2}$. The amine-amidine ligand forms a seven-membered chelate ring. One phenyl group is disordered. 


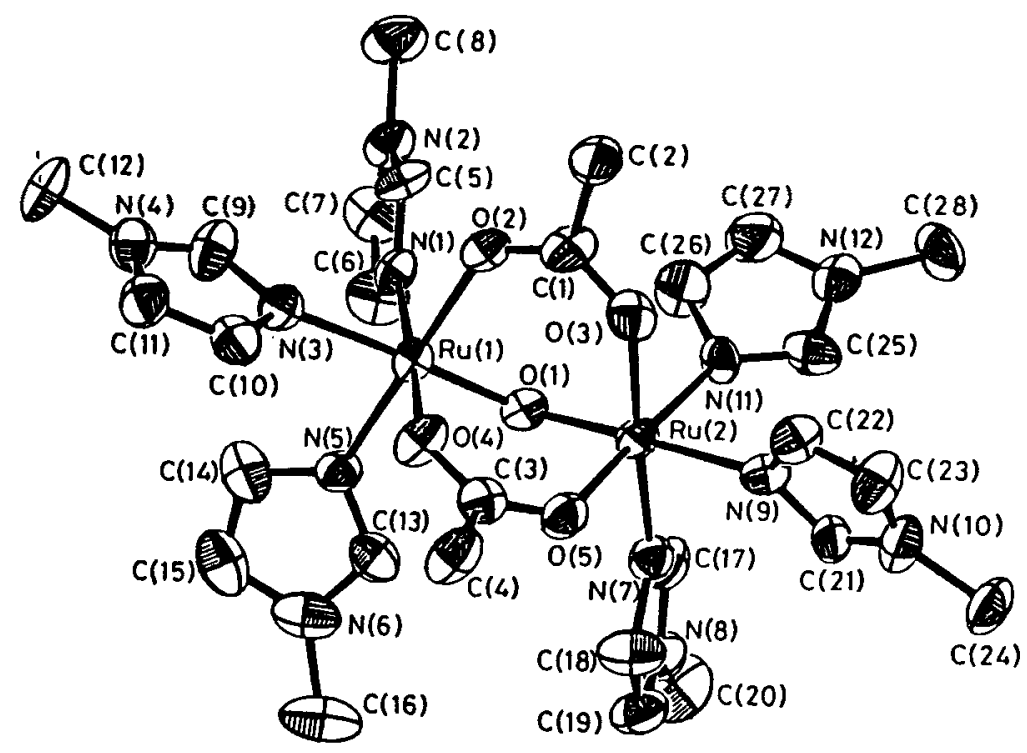

Figure 4. X-ray structure of $\left[\mathrm{Ru}_{2} \mathrm{O}\left(\mathrm{O}_{2} \mathrm{CMe}\right)_{2}(1-\mathrm{Meim})_{6}\right]\left(\mathrm{ClO}_{4}\right)_{2}$.

$\mu$-oxo ligand to form an amino-amidine ligand in $\left[\mathrm{Ru}_{2} \mathrm{O}\left(\mathrm{O}_{2} \mathrm{CR}\right)_{2}\left\{\mathrm{NH}_{2} \mathrm{CH}_{2} \mathrm{CH}_{2}\right.\right.$ $\left.\mathrm{NHC}(\mathrm{Me}) \mathrm{NH}\}_{2}\left(\mathrm{PPh}_{3}\right)_{2}\right]\left(\mathrm{ClO}_{4}\right)_{2}$ (figure 3) (Syamala and Chakravarty 1991). Under high thermal condition, a novel complex $\left[\mathrm{Ru}_{2} \mathrm{O}\left(\mathrm{O}_{2} \mathrm{CR}\right)_{3}(\mathrm{en})\left(\mathrm{PPh}_{3}\right)_{2}\right](\mathrm{ClO})_{4}$, showing an asymmetric disposition of the bidentate terminal ligands, has been isolated and characterized (Syamala et al 1995). The asymmetry makes the $\mathrm{Ru}-\mathrm{O}_{\text {oxo }}$ distances inequivalent giving a $\Delta r$ value of $0.04 \AA$. The presence of triphenylphosphine terminal ligands makes the core susceptible for cleavage to monomeric units and two monomers of compositions $\left[\mathrm{Ru}\left(\mathrm{O}_{2} \mathrm{CR}\right)(\mathrm{en})_{2}\left(\mathrm{PPh}_{3}\right)\right] \mathrm{X}_{2}\left(\mathrm{X}=\mathrm{ClO}_{4}, \mathrm{BPh}_{4}\right)$ and $\left[\mathrm{Ru}\left(\mathrm{O}_{2} \mathrm{CR}\right)\right.$ $\left.(\mathrm{en})_{2}\left(\mathrm{PPh}_{3}\right)\right]\left(\mathrm{ClO}_{4}\right)_{2}$ have been isolated (Syamala and Chakravarty 1995). All these tribridged complexes are redox active and undergo both oxidations and reductions. The reversibility of the oxidation process is better than that of the reduction (table 1 ). The reactions of $\mathrm{Ru}_{2} \mathrm{Cl}\left(\mathrm{O}_{2} \mathrm{CR}\right)_{4}$ with $\mathrm{PPh}_{3}$ leading to the formation of a variety of tribridged diruthenium(III) species are presented in scheme 1 (Syamala 1994).

\subsection{Tribridged species containing imidazole bases}

The diruthenium tetracarboxylates react with imidazole bases to form tribridged complexes containing six terminal imidazole bases (figure 4) (Sudha et al 1993). The complexes of formulation $\left[\mathrm{Ru}_{2} \mathrm{O}\left(\mathrm{O}_{2} \mathrm{CR}\right)_{2}(\mathrm{Rim})_{6}\right]\left(\mathrm{ClO}_{4}\right)_{2}(\mathrm{R}=\mathrm{H}, \mathrm{Me})$ exhibit interesting redox properties (figure 5 , table 1 ). The 1 -methylimidazole complexes in $0 \cdot 1 \mathrm{M}$ TBAP-MeCN show three responses near $1 \cdot 5,0.4$ and $-1 \cdot 1 \mathrm{~V}$ vs SCE. The voltammogram near $0.4 \mathrm{~V}$ corresponds to a one-electron reversible oxidation of the core and is assignable to the $\mathrm{Ru}_{2}(\mathrm{III}, \mathrm{III}) \rightleftharpoons \mathrm{Ru}_{2}$ (III, IV) couple. The second oxidation is quasireversible and gives a diruthenium(IV,IV) species. The one-electron oxidised product has also been isolated and characterised. It is interesting to note that the electron-transfer is highly reversible although the $\mathrm{Ru}-\mathrm{Ru}$ and $\mathrm{Ru}-\mathrm{O}_{\mathrm{oxo}}$ distances and the $\mathrm{Ru}-\mathrm{O}-\mathrm{R} \mathrm{u}$ angles in the $\left\{\mathrm{Ru}_{2}(\mu-\mathrm{O})^{n+}\right\}(n=4,5)$ units differ considerably from each 


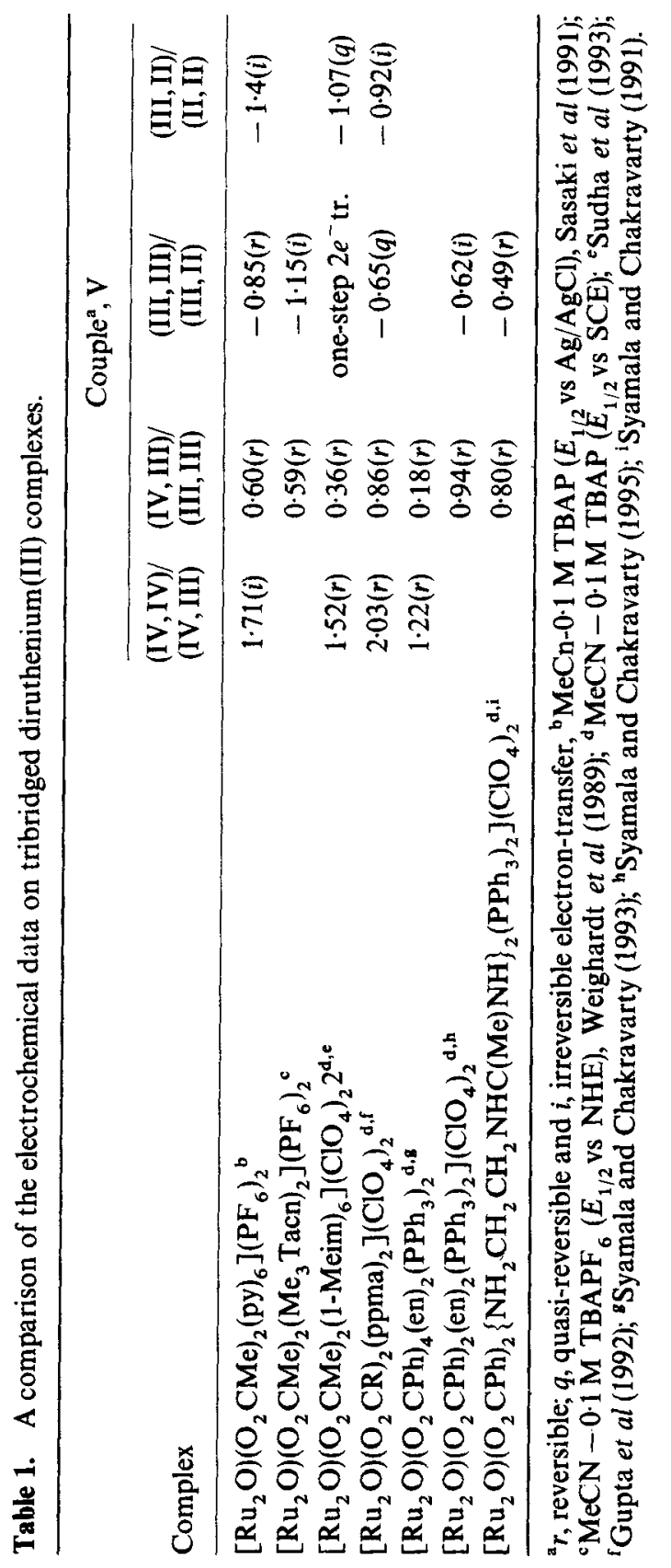




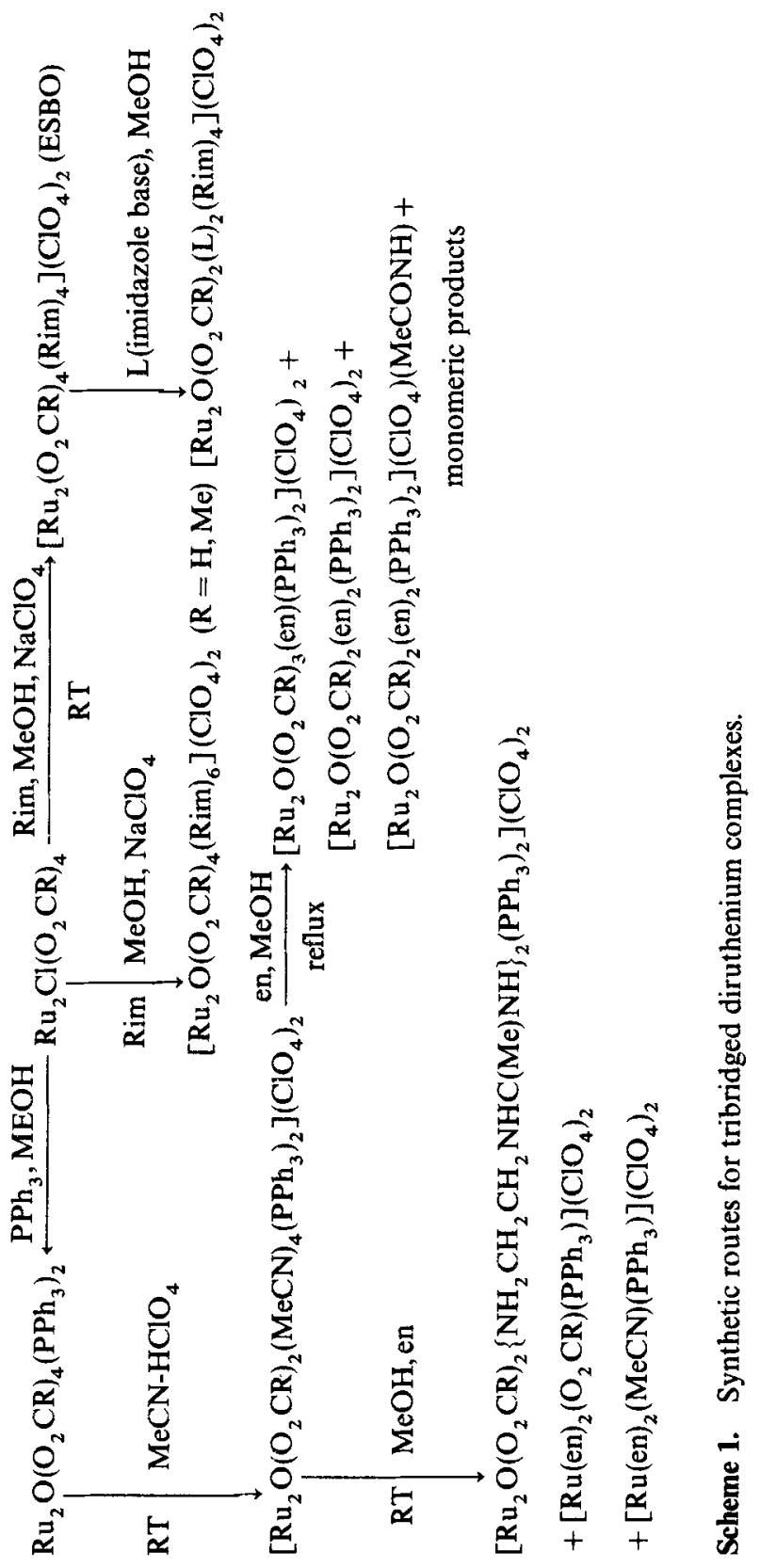



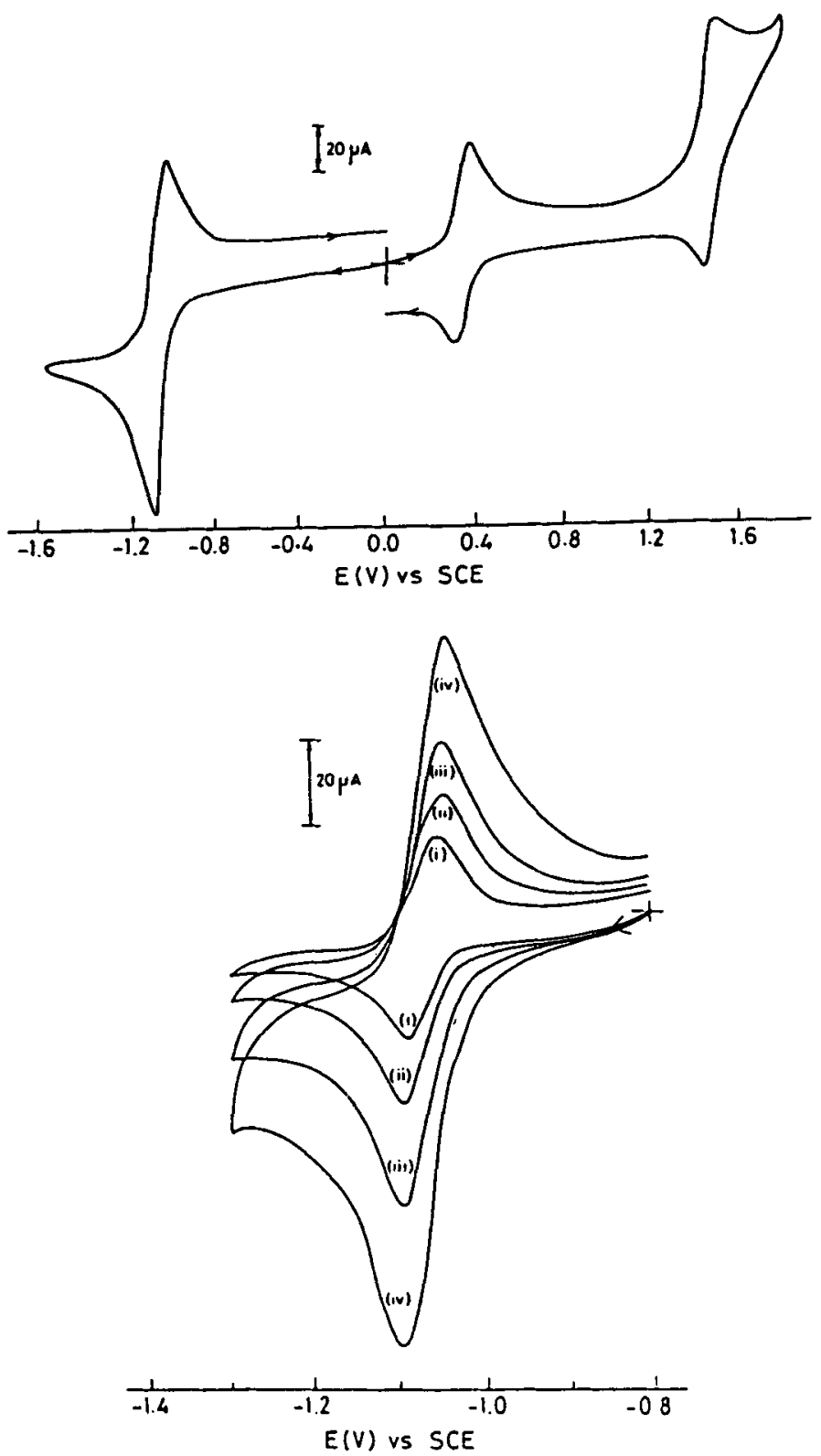

Figure 5. Cyclic voltammograms of $\left[\mathrm{Ru}_{2} \mathrm{O}\left(\mathrm{O}_{2} \mathrm{CMe}\right)_{2}(1-\mathrm{Meim})_{6}\right]-\left(\mathrm{ClO}_{4}\right)_{2}$ showing two one-electron oxidative and one two-electron reductive processes.

other. The reduction process observed near $-1 \cdot 1 \mathrm{~V}$ (vs SCE) corresponds to a one-step two-electron transfer process. The peak-to-peak separation $\left(\Delta E_{p}\right)$ of $30-50 \mathrm{mV}$ at $v=5-100 \mathrm{mVs}^{-1}$, the $i_{\mathrm{pc}} / i_{\mathrm{pa}}$ ratio of unity at various scan rates, and an $n$ value of 2.09 from the coulometric reduction at $-1.3 \mathrm{~V}$ indicate the quasireversible nature of the diruthenium(II, II) $\rightleftharpoons$ diruthenium(III, III) couple. The result is significant as a similar one-step $2 e^{-}$transfer process is previously unknown in the chemistry of tribridged 
dimetal model complexes with a $\left\{\mathrm{M}_{2}(\mu-\mathrm{O})\left(\mu-\mathrm{O}_{2} \mathrm{CR}\right)^{2+}\right\}$ core. The respiratory protein hemerythrin $(\mathrm{Hr}$ ) cycles between the diferrous (deoxyHr) and the diferric (oxyHr) forms. The two-electron transfer process resulting from the binding of a dioxygen molecule is extremely rapid and reversible. A similar redox process is presently unknown among the synthetic model $3 d-5 d$ metal complexes.

The redox behaviour of the imidazole complex is different from that of the 1methylimidazole species (Sudha and Chakravarty 1995, unpublished results). The imidazole complex $\left[\mathrm{Ru}_{2} \mathrm{O}\left(\mathrm{O}_{2} \mathrm{CR}\right)_{2}(\mathrm{Him})_{6}\right]\left(\mathrm{ClO}_{4}\right)_{2}$ undergoes only two successive one-electron oxidations and no reductions. The 4-methylimidazole complex also displays similar redox behaviour as that of the imidazole complex. It is rather intriguing that the LUMOs in the imidazole and 4-methylimidazole complexes are not accessible for electrochemical reduction when all other tribridged diruthenium(III) complexes are known to undergo electrochemical reduction of the core.

\section{Conclusions}

Complexes having a ( $\mu$-oxo)bis( $\mu$-carboxylato)dimetal core present a new structural motif in coordination chemistry. It is a general observation that the stabilization of such a core containing a $3 d$-metal atom needs the presence of facially blocking terdentate ligands at the terminal sites. In presence of unidentate terminal ligands the core undergoes conversion to complexes of higher nuclearity. However, the diruthenium core can be readily stabilized with unidentate ligands. The presence of unidentate terminal ligands makes these complexes suitable to study the effect of the terminal ligands on the electronic structure of the core. We are successful in the synthesis of a variety of tribridged diruthenium complexes containing unidentate terminal ligands by using a novel synthetic route. The 1,2-diaminoethane and imidazole complexes show interesting structures and electrochemical properties. The 1-Meim complexes display an unprecedented one-step two-electron transfer process. Further studies are in progress to rationalize this unusual redox phenomena.

\section{Acknowledgement}

This work was funded by the Department of Science and Technology, Government of India. Thanks are due to my students and co-workers, Drs B K Das, S K Mandal, A Syamala and C Sudha for carrying out the research work presented in this article.

\section{References}

Barral M C, Jimenez-Aparicio R, Kramalowsky R and Wagner I 1993 Polyhedron 12903

Cannon R D and White R P 1988 Prog. Inorg. Chem. 36195

Cotton F A and Walton R A 1993 Multiple bonds between metal atoms (Oxford: University Press)

Das B K and Chakravarty A R 1990 Inorg. Chem. 292078

Gupta N, Mukherjee S, Mahapatra S, Ray M and Mukherjee R 1992 Inorg. Chem. 31139

Kurtz D M Jr 1990 Chem. Rev. 90585

Llobet A, Curry M E, Evans H T and Meyer T J 1989 Inorg. Chem. 283131

Que L Jr and True A E 1990 Prog. Inorg. Chem. 3897

Sasaki Y, Suzuki M, Nagasawa A, Tokiwa A, Ebihara M, Yamaguchi 'T, Kabuto C, Ochi T and Ito T 1991 Inorg. Chem. 304903

Stenkamp R E, Sieker L C and Jensen L H 1984 J. Am. Chem. Soc. 106618 
Sudha C, Mandal S K and Chakravarty A R 1993 Inorg. Chem. 323801

Syamala A 1994 Aspects of the chemistry of ( $\mu$-oxo) bis ( $\mu$-carboxylato) diruthenium complexes,

$\mathrm{Ph} \mathrm{D}$ thesis, Department of Inorganic \& Physical Chemistry, Indian Institute of Science, Bangalore

Syamala A and Chakravarty A R 1991 Inorg. Chem. 304699

Syamala A and Chakravarty A R 1993 Polyhedron 121545

Syamala A and Chakravarty A R 1995 Polyhedron 14231

Syamala A, Nethaji M and Chakravarty A R 1995 Inorg. Chim. Acta 21933

Wieghardt K 1989 Angew. Chem.. Int. Ed. Eng. 281153

Wieghardt K 1994 Angew. Chem. 106765

Wieghardt K, Bossek U, Neves A, Nuber B and Weiss J 1989 Inorg. Chem. 28432 